\title{
Healthcare Reform: Implications for Mental Health in Rural America
}

\author{
GREGORY WISNIEWSKI ${ }^{1}$ \\ ${ }^{1}$ College of Public Health, Temple University \\ Correspondence: greg.wisniewski@temple.edu (Gregory Wisniewski)
}

Rural Americans are significantly impacted by mental health issues. Reform is needed to bring appropriate aid. The Biden Administration's Public Option and Representatives Pramila Jayapal and Debbie Dingell's Medicare for All Act of 2021 aim to improve the United States' health care system and offer such reform.

\section{Introduction}

Rural Americans have similar mental health disorder prevalence rates to urban Americans, but their suicide death rate is substantially higher (17.32 per 100,000 people; 11.92 per 100,000 people). ${ }^{1}$ This discrepancy is attributed to rural communities having characteristics that are also suicide risk factors such as lack of affordable care, access to treatment, and insurance coverage. ${ }^{2}$ The Biden Administration's Public Option and Representatives Pramila Jayapal and Debbie Dingell's Medicare for All Act of 2021 are the two pieces of legislation that can bring reform. ${ }^{3-4}$

\section{Affordability, Access, and Economics}

Ten million rural Americans are living at or below the federal poverty line. ${ }^{1}$ Despite this, rural Americans pay $40 \%$ higher premiums for the ACA's silver plans than their urban counterparts. ${ }^{5}$ This is due to the lack of competition in rural areas; of the 650 counties that only have one insurer in the Marketplace, $70 \%$ are in rural areas. ${ }^{6}$ In reaction to this, many individuals opt into the lower premium, higher deductible bronze plans. When these individuals get sick or have a medical condition, they often are stuck with expensive bills. ${ }^{5}$ Rural Americans not only struggle with access to insurance but also providers. Sixty-five percent of non-metropolitan counties do not have a psychiatrist, and $47 \%$ do not have a psychologist. ${ }^{7}$ Untreated mental illness accounts for up to $90 \%$ of suicides. ${ }^{8}$

The average cost of one suicide is $\$ 1.3$ million. ${ }^{9}$ The total direct and indirect costs of suicide attempts in 2013 were $\$ 93$ billion. Loss of productivity contributed to $97 \%$ of these costs. Rural areas already affected by healthcare shortages, lack of employment opportunities, and general lack of access to resources cannot afford the loss of life, perpetuation of trauma, and economic hardship that untreated mental health causes. The Biden Administration's Public Option and Representatives Pramila Jayapal and Debbie Dingell's Medicare for All Act of 2021 address these concerns. 


\section{Public Option}

The Public Option offers citizens insurance similar to Medicare; it will cover inpatient and outpatient mental health and substance abuse disorders services. ${ }^{3}$ The Public Option will be premium-free to citizens below $138 \%$ of the federal poverty line. The Public Option also increases coverage and affordability by expanding the Affordable Care Act's subsidies, calculating said tax credit on the superior gold plan's cost rather than the current tax credit, which uses the silver plan. ${ }^{3}$ The change reduces the premium of the gold plan. This is significant because the gold plan has $80 \%$ approximate coverage and no deductible. ${ }^{10}$ The silver plan offers 70\% approximate coverage and $\$ 2,250$ medical and $\$ 250$ prescription deductibles.

The Public Option will also enforce The Mental Health Parity and Addiction Equity Act, which states insurers must cover mental health treatment equal to other medical services. ${ }^{3}$ In addition, the Public Option addresses access to care through funding, allocating $\$ 50$ million for community health centers, employing mental health professionals, increasing education, decreasing stigma, and additional mental health services. ${ }^{3}$ Another $\$ 50$ million is allotted "for the construction, expansion, and improvement of mental health facilities" in rural areas.

\section{Medicare for All}

The Medicare for All Act increases access and affordability by automatically enrolling all individuals in a single-payer-federal program. ${ }^{4}$ This program provides extensive lifetime coverage with no premiums. It includes inpatient and all other necessary treatment for mental health and substance abuse. It is unclear what is considered "necessary" as the bill provides no further context. Ideally, coverage would expand upon traditional Medicare, covering individual and group therapy, inpatient hospitalizations, medication management, and residential services. The Medicare for All Act does not explicitly provide any mental health funding. However, it saves an estimated $\$ 700$ billion annually by cutting administrative costs, eliminating insurance profiteering, and negotiating drug prices. ${ }^{4}$

\section{Conclusion}

The Public Option and Medicare for All Act of 2021 are transformational policies. The Public Option reduces costs to individuals through a government-run plan. The Medicare for All Act automatically enrolls all individuals for life in an entirely new federal single-payer program. Implementing each policy poses serious challenges. The fragmentation and polarization in the US government is an inhibitor to progress. These policies should not be looked at as two separate decisions but stages of the same option. The Public Option is not the solution but a stepping stone to a better system. This better system could be Medicare for All or something else entirely but we will not know until we move forward.

\section{Disclosures and Conflicts of Interest}

I am currently an employee for Rogers Behavioral Health located in Wisconsin. Many of the patients Rogers serves are from rural areas. 


\section{Acknowledgments}

I would like to extend my appreciation to Dr. David B. Sarwer and Professor Hamlet Gasoyan for their support and guidance.

\section{References}

1. Rural mental health introduction - rural health information hub. Ruralhealthinfo.org. Accessed May 27, 2021. https://www.ruralhealthinfo.org/topics/mental-health

2. Suicide in Rural Areas - RHIhub Toolkit. Ruralhealthinfo.org. Accessed September 14, 2021. https://www.ruralhealthinfo.org/toolkits/suicide/1/rural

3. Plan to protect and build on Obamacare. Joebiden.com. Published July 14, 2019. Accessed May 27, 2021. https://joebiden.com/healthcare/.

4. The Medicare for All Act of 2021. Pnhp.org. Published March 17, 2021. Accessed May 27, 2021. https://pnhp.org/the-medicare-for-all-act-of-2021/.

5. HealthLeaders. ACA premiums costlier in rural America. Healthleadersmedia.com. Accessed May 27, 2021. https://www.healthleadersmedia.com/aca-premiums-costlier-rural-america

6. Nganje W, Addey KA. Health Uninsurance in rural America: a partial equilibrium analysis. Health Econ Rev. 2019;9(1):19.

7. Andrilla CHA, Patterson DG, Garberson LA, Coulthard C, Larson EH. Geographic variation in the supply of selected behavioral health providers. Am J Prev Med. 2018;54(6 Suppl 3):S199S207.

8. Key Facts About Mental Illness. Clubhouse-intl.org. Accessed May 27, 2021. http://clubhouseintl.org/our-impact/about-mental-illness/key-facts-about-mental-illness/

9. Costs of Suicide. Sprc.org. Accessed September 13, 2021. https://www.sprc.org/aboutsuicide/costs

10. De Vore A. Comparing exchange plans: Bronze, Silver, Gold, Platinum - medicoverage.Com. Published online 2015. Accessed September 13, 2021. https://www.medicoverage.com/healthinsurance-blog/news/comparing-exchange-plans-bronze-silver-gold-platinum 